\title{
Mast cells and type VIII collagen in human diabetic nephropathy
}

\author{
B. M. Rüger, Q. Hasan, N. S. Greenhill, P. F. Davis, P. R. Dunbar, T. J. Neale \\ Department of Medicine, Wellington School of Medicine, Wellington South, New Zealand
}

\begin{abstract}
Summary Renal injury in diabetes mellitus is associated with progressive interstitial fibrosis and extracellular matrix accumulation. However, the phenotypes of cells forming the interstitial infiltrate in diabetic nephropathy have not been precisely defined. There is increasing evidence for the association of mast cells with angiogenesis, chronic inflammatory conditions and fibrosis. We have recently shown that human mast cells can produce the non-fibrillar short chain type VIII collagen in vivo. Using immunohistochemistry, in situ hybridisation and reverse transcriptasepolymerase chain reaction, we examined the contribution of mast cells and type VIII collagen to the fibrotic changes occurring in biopsy-proven diabetic nephropathy. We observed that the number of interstitial mast cells was significantly increased in diabetic nephropathy compared with normal kidney tissue. In specimens from diabetic subjects, intense immunohistochemical staining for type VIII collagen
\end{abstract}

Received: 27 November 1995 and in revised form: 24 April 1996

Corresponding author: B.M. Rüger, Department of Medicine, Wellington School of Medicine, P.O. Box 7343, Wellington South, Wellington, New Zealand

Abbreviations: MC, Mast cells; DN, diabetic nephropathy; IDDM, insulin-dependent diabetes mellitus; NIDDM, non-insulin-dependent diabetes mellitus; RT-PCR, reverse transcriptase-polymerase chain reaction; $\mathrm{mAb}$, monoclonal antibody; $\alpha$ SMA, alpha smooth muscle actin; BSA, bovine serum albumin; PAP, peroxidase anti-peroxidase; PBS, phosphate buffered saline; RNase A, ribonuclease A; SSC, standard saline citrate; NBT/X phosphate, nitroblue tetrazolium/alkaline phosphate; TAE, tris acetate ethylene diamine tetraacetic acid; bp, base pairs; HPRT, hypoxanthine phosphoribosyl transferase, was detected in mast cells, on periglomerular fibres and in perivascular and interstitial sites. The expression of type VIII collagen in periglomerular and interstitial sites coincided with that of alpha smooth muscle actin, a marker for myofibroblastic differentiation. mRNA for type VIII collagen was detected by reverse transcriptase-polymerase chain reaction in diabetic nephropathy and in a human mast cell line. By in situ hybridisation the transcripts for type VIII collagen were localised to renal mast cells. The increased number of mast cells and the elevated type VIII collagen deposition in human diabetic nephropathy provides a potential link between the extracellular matrix accumulation and the fibrosis observed in this condition. [Diabetologia (1996) 39: 1215-1222]

Keywords Mast cells, type VIII collagen, diabetic nephropathy, extracellular matrix, immunohistochemistry.
Diabetic nephropathy (DN) is characterised by a complex accumulation of extracellular matrix proteins, resulting in diffuse glomerular sclerosis and progressive tubulointerstitial fibrosis [1]. In diabetes there is an increased production and a reduced degradation of extracellular matrix constituents leading to their overall accumulation [2]. Many studies of DN have aimed at defining intraglomerular changes [36], but the mechanisms of tubulointerstitial matrix abnormalities have been infrequently considered [2]. Although several studies have attempted to define the nature of the components of extracellular matrix which accumulates in a variety of experimental and human nephropathies $[1,7-10]$, knowledge in this area is still rudimentary. Furthermore, the phenotypes of cells forming the interstitial infiltrate in DN 
have not been precisely defined. Previously mast cells (MC) have been identified only rarely in the kidney $[11,12]$. MC have been implicated in fibrosis in rheumatoid arthritis, some forms of pulmonary fibrosis, and inflammatory bowel disease $[13,14]$. It has been reported that murine $\mathrm{MC}$ can produce basement membrane components [15], and in a recent study [16] we have shown that human MC are capable of producing type VIII collagen in vivo.

Type VIII collagen is a non-fibrillar short-chain collagen that forms a specialised polymeric network. It was first identified in cell culture medium of bovine aortic endothelial cells [17] and is the principal component of the hexagonal lattice in Descemet's membrane of the eye [18]. It is also expressed in sclera and choroid, optic nerve sheath, periosteum, perichondrium, meninges, and the subendothelial layer of blood vessels [19-21]. In angiogenesis, type VIII collagen is believed to facilitate the assembly of endothelial cords and tubes [22, 23], and its synthesis precedes or coincides with that of type I procollagen [24]. In the rat kidney type VIII collagen is expressed by mesangial cells, and it has been suggested that it polymerises and interacts with other matrix components [25].

Based on the increasing evidence that $\mathrm{MC}$ are involved in angiogenesis and fibrosis and on our previous finding that they are able to produce type VIII collagen in vivo, we have investigated the contribution of MC to the tubulointerstitial changes and collagen deposition associated with human DN.

\section{Subjects, materials and methods}

Samples. Renal biopsy tissue, evaluated by an independent pathologist, was available from 20 patients with DN and from five non-diabetic control subjects without diagnostic abnormalities. Sixteen of the DN patients had non-insulin-dependent diabetes mellitus (NIDDM; 11 male, age range 3968 years, mean 54 years), while four had insulin-dependent diabetes mellitus (IDDM; 2 male, age range 33-57 years, mean 46 years). Duration of diabetes ranged up to 15 years (mean 4 years) and four patients had been recently diagnosed. Serum creatinine ranged from 80 to $1230 \mathrm{mmol} / \mathrm{l}$, while proteinuria ranged from 1 to $19 \mathrm{~g} /$ day. Histological changes in $\mathrm{DN}$ biopsies were scored according to severity of interstitial and periglomerular fibrosis: fibrosis was severe in 11 cases, moderate in 5 cases, and mild in 4 cases.

Biopsy cores were divided, one part was fixed in $4 \%$ formalin and embedded in paraffin, while a second was snap-frozen in liquid nitrogen and stored at $-70^{\circ} \mathrm{C}$. All subjects gave informed written consent and the study was approved by the Ethical Committee of the Wellington Area Health Board.

Cells. The human mast cell line, HMC-1 (kindly provided by J.H.Butterfield, Mayo Clinic, Rochester, Minn., USA) [26] was cultured in Iscove's medium supplemented with $10 \%$ heat-inactivated calf serum (Hyclone, Logan, Utah, USA) and $1.2 \mathrm{mmol} / \mathrm{l}$ alphathioglycerol (Sigma, St.Louis, Mo, $\mathrm{USA}$ ) at $5 \% \mathrm{CO}_{2}, 37^{\circ} \mathrm{C}$.
Antibodies. A monoclonal antibody (mAb) to the $\alpha 1$-chain of type VIII collagen ( $\alpha 1$ (VIII) collagen), 9H3 (gift of H. Sawada, Yokohama Medical School, Yokohama, Japan) diluted $1: 100$, was used to study the expression of type VIII collagen [18]. The deposition of interstitial collagens I, III and V was examined using goat polyclonal antibodies to human/bovine collagens (Southern Biotechnology, Birmingham, Ala., USA) at dilutions $1: 100,1: 400$ and $1: 100$ respectively. MC phenotyping was performed using $m$ Abs with specificity for human tryptase ( $1: 2000$ dilution) and chymase (1:200 dilution) (Chemicon, Temecula, Calif., USA), c-kit (1:500 dilution) (gift of L. Ashman, The Hanson Centre for Cancer Research, Adelaide, SA, Australia) and the high affinity receptor for $\operatorname{IgE}, \mathrm{Fcc} \mathrm{R} 1$, clone15A5 (1:200 dilution) (gift of R. Chizzonite, Hoffman-LaRoche Inc., Nutley, N.J., USA) [27]. HHF35 (Enzo, New York, N. Y., USA), a mAb reactive with alpha smooth muscle actin ( $\alpha$ SMA), diluted 1:6000, was used to demonstrate the differentiation of fibroblasts into myofibroblasts [28]. All anti-

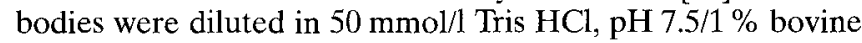
serum albumin (BSA).

Immunohistochemistry. Immunostaining on formalin-fixed, paraffin-embedded biopsies was performed as previously reported [16]. The sections were de-waxed and endogenous peroxidase activity quenched with $0.3 \%$ hydrogen peroxide. For the detection of type VIII collagen and MC tryptase, tissues were pre-digested at $37^{\circ} \mathrm{C}$ with $3850 \mathrm{U} / 1$ pepsin (Sigma) in $10 \mathrm{mmol} / \mathrm{l}$ $\mathrm{HCl}$ for $1 \mathrm{~h}$. For all other antibodies, $0.05 \%$ protease XXIV (Sigma) in $50 \mathrm{mmol} / 1$ Tris $\mathrm{HCl} \mathrm{pH} \mathrm{7.5,} \mathrm{for} 10 \mathrm{~min}$ at $37^{\circ} \mathrm{C}$ was used. Control sections were further digested with $1 \mathrm{mg} / \mathrm{ml}$ purified collagenase (type VII, Sigma) in $100 \mathrm{mmol} / \mathrm{l} \mathrm{NaCl}$ for $1 \mathrm{~h}$ at $50^{\circ} \mathrm{C}$. The sections were incubated with the primary antibodies for $1 \mathrm{~h}$ at room temperature, or overnight at $4{ }^{\circ} \mathrm{C}$. Controls included omission of primary antibody and substitution with an irrelevant $\mathrm{mAb}$ of the same isotype, or with normal rabbit or goat serum for polyclonal antibodies. $m$ Ab binding was detected with a sensitive three-step immunoperoxidase technique, using peroxidase-conjugated rabbit anti-mouse IgG (DAKO, Carpinteria, Calif., USA), and peroxidase-conjugated swine antirabbit IgG (DAKO), both diluted $1: 20$ with $50 \%$ heat-inactivated human serum. The reactivity of polyclonal antibodies was revealed using swine anti-rabbit or rabbit anti-goat immunoglobulins (DAKO) $(1: 100)$ as bridging reagents followed by rabbit or goat peroxidase anti-peroxidase (PAP) (DAKO) $(1: 50)$ respectively. The sections were exposed to $0.05 \%$ diaminobenzidine in $50 \mathrm{mmol} / \mathrm{l} \mathrm{Tris} \mathrm{HCl}, \mathrm{pH} 7.5$, counterstained with haematoxylin, dehydrated, and mounted in DPX mounting medium (DPX) (BDH, Poole, Dorset, UK). For frozen acetone-fixed tissues the pre-digestion steps were omitted, and the secondary reagents were used in $1: 100$ dilution.

Reverse transcriptase-polymerase chain reaction $(R T-P C R)$. Total RNA from seven snap-frozen DN biopsies and from three control kidneys were extracted using TRIzol Reagent (GIBCO, BRL, Gaithersburg, Md., USA). RNA was similarly isolated from an HMC-1 cell line and treated with heparinase I (Sigma) according to the method of Tsai et al. [29]. RNA was amplified using the Perkin Elmer Tth RT-PCR kit (Norwalk, Ct, USA), with a 10 -min RT step followed by 50 cycles of three-stage PCR (annealing at $52^{\circ} \mathrm{C}$ ) in a Perkin Elmer 9600 machine. PCR products were electrophoresed on $2 \%$ agarose gels in tris acetate ethylene diamine tetraacetic acid (TAE). Exon-spanning primers were designed to amplify $\alpha 1$ (VIII) collagen mRNA (sense 5'-GCTTACCATTTCCCTGAGTTCC3' and anti-sense 5'-CCAATT'TCCCCITTCTGTCC-3', predicted product 522 base pairs (bp) and synthesized by Operon Technologies (Alameda, Calif., USA). 

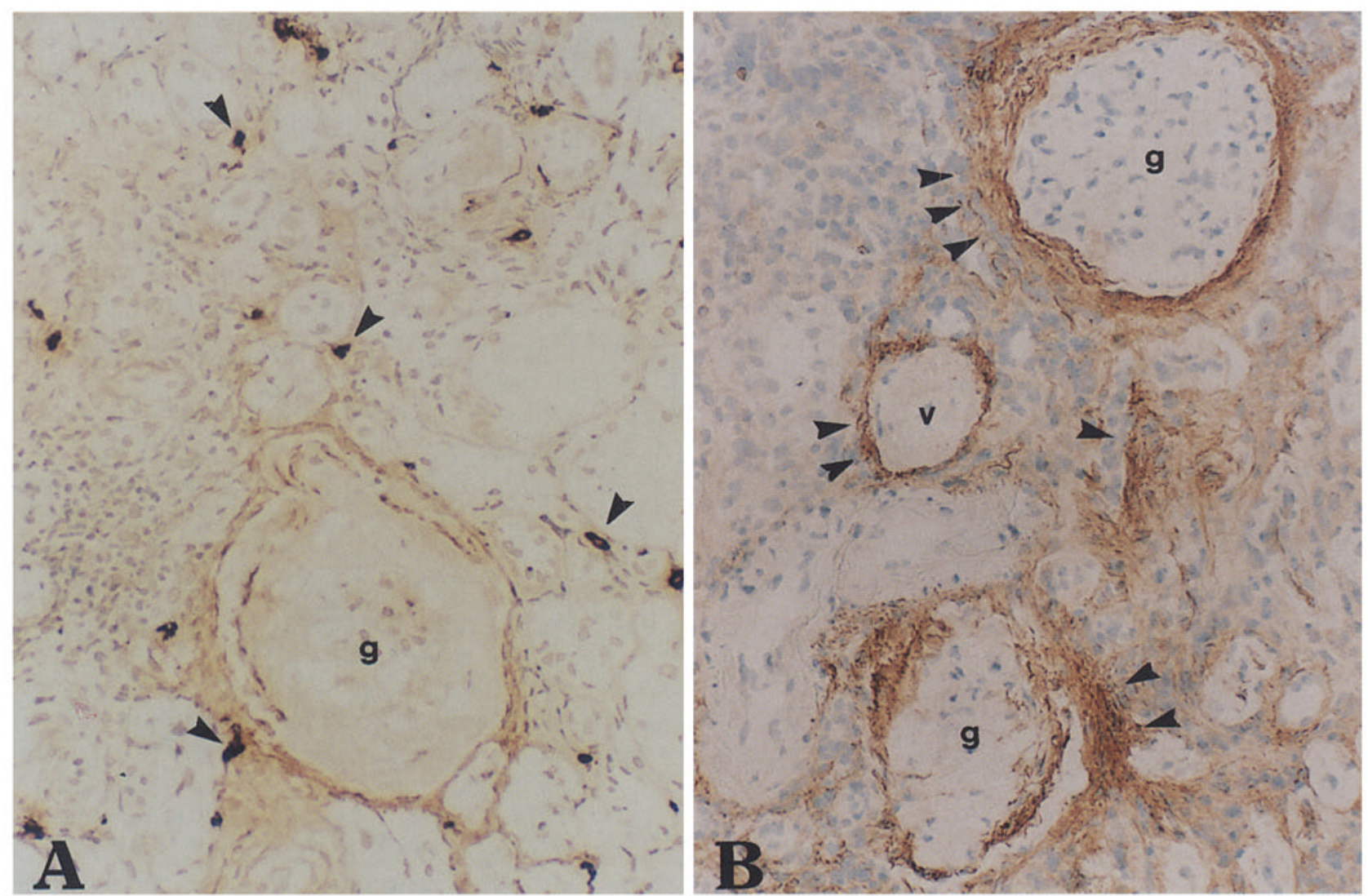

Fig. 1. Type VIII collagen expression in diabetic nephropathy. Interstitial cells (A, arrows) and periglomerular, perivascular and interstitial fibres (B, arrows) were labelled with an anti-

body against $\alpha 1$ (VIII) collagen. (Immunoperoxidase staining; $\mathbf{A}$, paraffin embedded tissue, $\mathbf{B}$, frozen tissue; magnification $\times 175$; g, glomerulus; v, vessel)
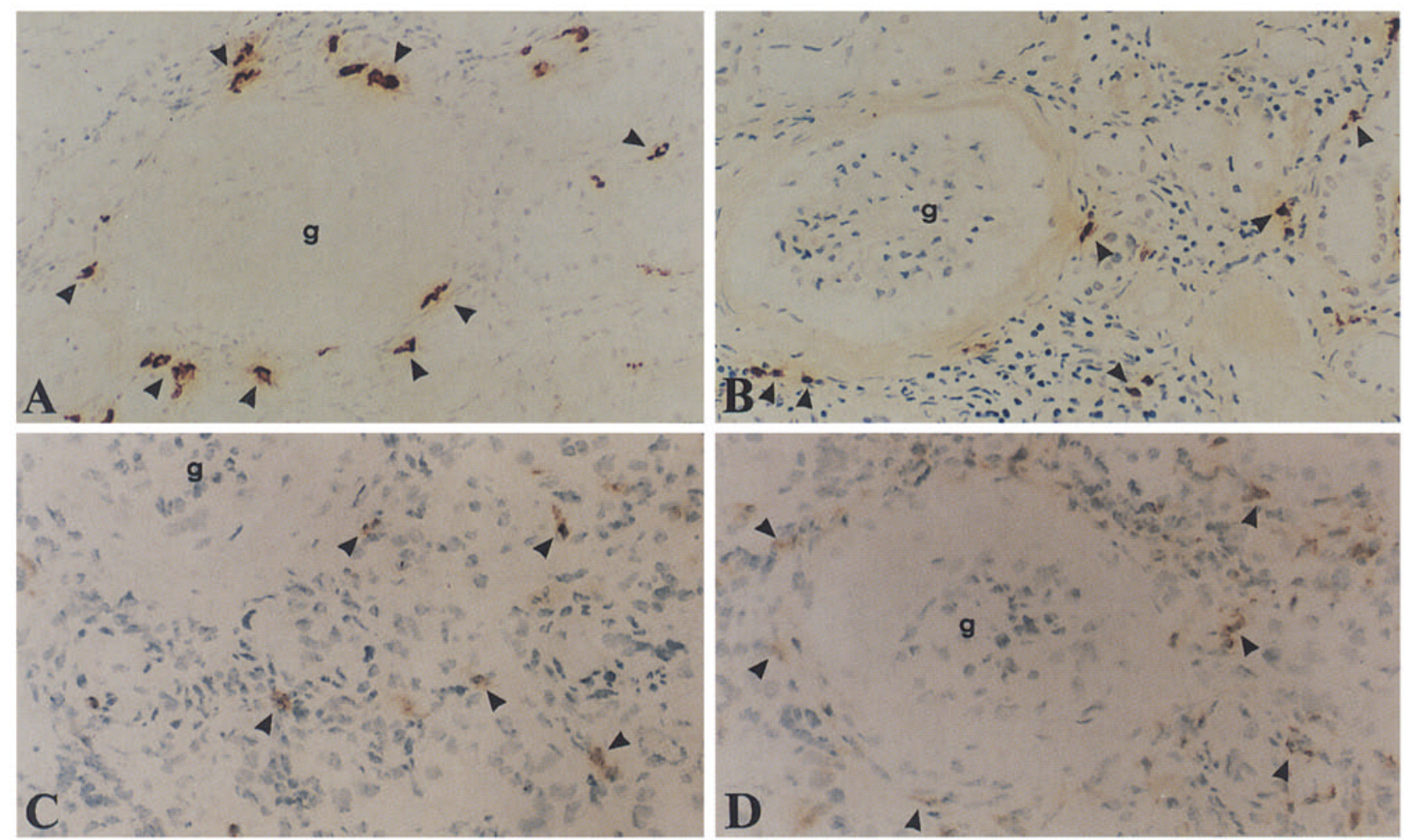

Fig. 2. Immunohistochemical phenotyping of $\mathrm{MC}$ in diabetic nephropathy. Interstitial cells expressed human tryptase (A), human chymase (B), c-kit (C) and Fc $\varepsilon$ R1 (D), as indicated by

arrows, identifying them as MC. Note the MC in periglomerular areas. (Immunoperoxidase staining; A, B paraffin embedded tissue; $\mathbf{C}, \mathbf{D}$ frozen tissue; magnification $\times 175$; g, glomerulus) 
Prior to assessing the presence of $\alpha 1$ (VIII) collagen mRNA in renal tissue, the amount of mRNA coding for a housekeeping gene was equalised in each sample by competitive RTPCR [30]. Briefly, exon-spanning primers were designed (sense 5'-CCTTTGGGCGGATTGTTGT-3' and anti-sense 5''TTTITTTTTTTTTTAAATTTTTGGGAAT-3', predicted product $395 \mathrm{bp}$ ) to amplify mRNA coding for hypoxanthine phosphoribosyl transferase (HPRT), a constitutively-expressed gene present at constant low copy number [31]. A DNA fragment which amplified as a 380 -bp product using the HPRT primers was generated by low stringency PCR of chimpanzee genomic DNA, followed by purification with glass milk (Prepagene, BioRad, Richmond, Calif., USA) after agarose gel electrophoresis [32]. Serial dilutions of each RNA sample were subjected to RT-PCR for HPRT in the presence of a fixed dilution of the DNA fragment, which acted as a competitor template. After establishing the dilution of each RNA sample required to generate an equivalent signal to the DNA competitor, these dilutions were subjected to RT-PCR for $\alpha 1$ (VIII) collagen.

In situ hybridisation. Oligonucleotide probes based on the published human $\alpha 1$ (VIII) collagen sequence [33] were used as previously reported [16]. The probes were 3-labelled with digoxigenin using the Boehringer Mannheim oligonucleotide tailing kit (Boehringer Mannheim, Mannheim, Germany).

Formalin-fixed paraffin sections were digested with $1.5 \mu \mathrm{g} /$ $\mathrm{ml}$ proteinase $\mathrm{K}$ (Boehringer Mannheim) for $1 \mathrm{~h}$ at $37^{\circ} \mathrm{C}$, post-fixed in $0.4 \%$ paraformaldehyde in phosphate buffered saline (PBS) for $20 \mathrm{~min}$ at $4{ }^{\circ} \mathrm{C}$ and acetylated for $10 \mathrm{~min}$ in $0.25 \%$ acetic anhydride in triethanolamine. Control slides were incubated with $100 \mu \mathrm{g} / \mathrm{ml}$ RNase A (Boehringer Mannheim) for $1 \mathrm{~h}$ at $37^{\circ} \mathrm{C}$. Pre-hybridisation for $1 \mathrm{~h}$ at $37^{\circ} \mathrm{C}$ was followed by overnight hybridisation at $37^{\circ} \mathrm{C}$, either with $200 \mathrm{ng}$ of the two anti-sense probes (in an equimolar mixture), or with $200 \mathrm{ng}$ of the sense probe. After several stringency washes with $2 \mathrm{X}$ standard saline citrate (SSC) and $0.2 \mathrm{XSSC}$ at $22^{\circ} \mathrm{C}$, the hybridised probes were detected using alkaline phosphatase-labelled anti-digoxigenin antibody diluted 1:500 in Tris buffer/BSA for $1 \mathrm{~h}$ at room temperature, and nitroblue tetrazolium/alkaline phosphate (NBT/X-phosphate) substrate according to the manufacturer's instructions (Boehringer Mannheim). Slides were counterstained with neutral red, air dried, and mounted in DPX.

\section{Statistical analysis}

Cells positive for tryptase, chymase and type VIII collagen were counted in five medium power fields $(\times 50)$ using a 25 point Zeiss (Jena, Germany) integrating grid. Statistical evaluation was carried out using Student's $t$-test.

\section{Results}

All 20 biopsies studied by immunohistochemistry contained a variable number of interstitial cells that stained for type VIII collagen (Fig. 1 A). Immunohistochemical phenotyping identified these cells as MC. Most contained the two serine proteases tryptase and chymase (Fig. 2 A, B), a characteristic feature of human connective tissue type MC [34]. These MC also expressed c-kit, the receptor for stem cell factor
Table 1. Number of mast cells (tryptase, chymase positive) and type VIII collagen (9H3) positive cells in diabetic nephropathy and normal human kidney tissue

\begin{tabular}{llll}
\hline & $\begin{array}{l}\text { Diabetic nephro- } \\
\text { pathy }(n=20)\end{array}$ & $\begin{array}{l}\text { Normal } \\
(n=5)\end{array}$ & $p$-value \\
\hline $\begin{array}{l}\text { Tryptase } \\
\text { positive }\end{array}$ & $\begin{array}{l}12.7 \pm 9.5 \\
\text { (range } 2-33)\end{array}$ & $\begin{array}{l}1.6 \pm 0.4 \\
\text { (range 0-3) }\end{array}$ & $(<0.01)$ \\
Chymase & $\begin{array}{l}10.2 \pm 8.4 \\
\text { (range } 2-28)\end{array}$ & $\begin{array}{l}1.0 \pm 0.5 \\
\text { (range 0-3) }\end{array}$ & $(<0.05)$ \\
$\begin{array}{l}\text { Type VIItive } \\
\text { positive }\end{array}$ & $\begin{array}{l}\text { (range } 2-30) \\
\text { (range 0-3) }\end{array}$ & $(<0.01)$ \\
\hline
\end{tabular}

Values are $n$ cells/five fields \pm SD

(Fig. 2C), and $F c \varepsilon R 1$, the high affinity receptor for IgE (Fig. 2D). Degranulating MC could be observed frequently (Fig. 3). MC were often detected in periglomerular areas, but not within glomeruli (Fig. 2 A). There was a significant increase of total $\mathrm{MC}$ number (tryptase positive) in DN compared to normal biopsies as well as an increased number of MC expressing type VIII collagen (Table 1). In addition, $10 \mathrm{DN}$ biopsies expressed type VIII collagen on periglomerular fibres, in interstitial areas and around blood vessels (Fig.1B). No differences were evident between tissue samples from patients with IDDM and NIDDM. There was no correlation between periglomerular and interstitial type VIII collagen staining and any clinical characteristic (age, gender, duration of diabetes, serum creatinine concentration, or degree of proteinuria). Periglomerular and interstitial type VIII collagen staining was generally associated with more severe overall interstitial fibrosis. However, this was an imperfect association, since some severely fibrosed specimens did not stain for type VIII collagen in these locations.

Samples without diagnostic abnormalities showed type VIII collagen staining only around blood vessels (Fig.4) and contained only occasional MC. Collagenase treatment of control and $\mathrm{DN}$ tissue sections completely abrogated staining with $9 \mathrm{H} 3$ antibody, but did not affect the reactivity with tryptase antibody, thus confirming the collagenous nature of the antigen (Fig.5). Staining for type I collagen showed a similar distribution to type VIII collagen in the extracellular matrix, but was not observed in MC (data not shown). Type III and V collagens were also absent from MC, but showed increased interstitial deposition in DN (data not shown), confirming previous reports $[5,35]$.

RT-PCR revealed the presence of $\alpha 1$ (VIII) collagen mRNA in DN biopsies, producing the predicted 522 bp band. This band was absent from specimens without diagnostic abnormalities, although these samples generated an equivalent signal from the housekeeping gene HPRT in competitive RTPCR (Fig. 6). Heparinase pre-treatment of RNA from the HMC-1 cells enabled the detection of $\alpha 1$ (VIII) collagen mRNA (Fig. 6). By non-isotopic in 


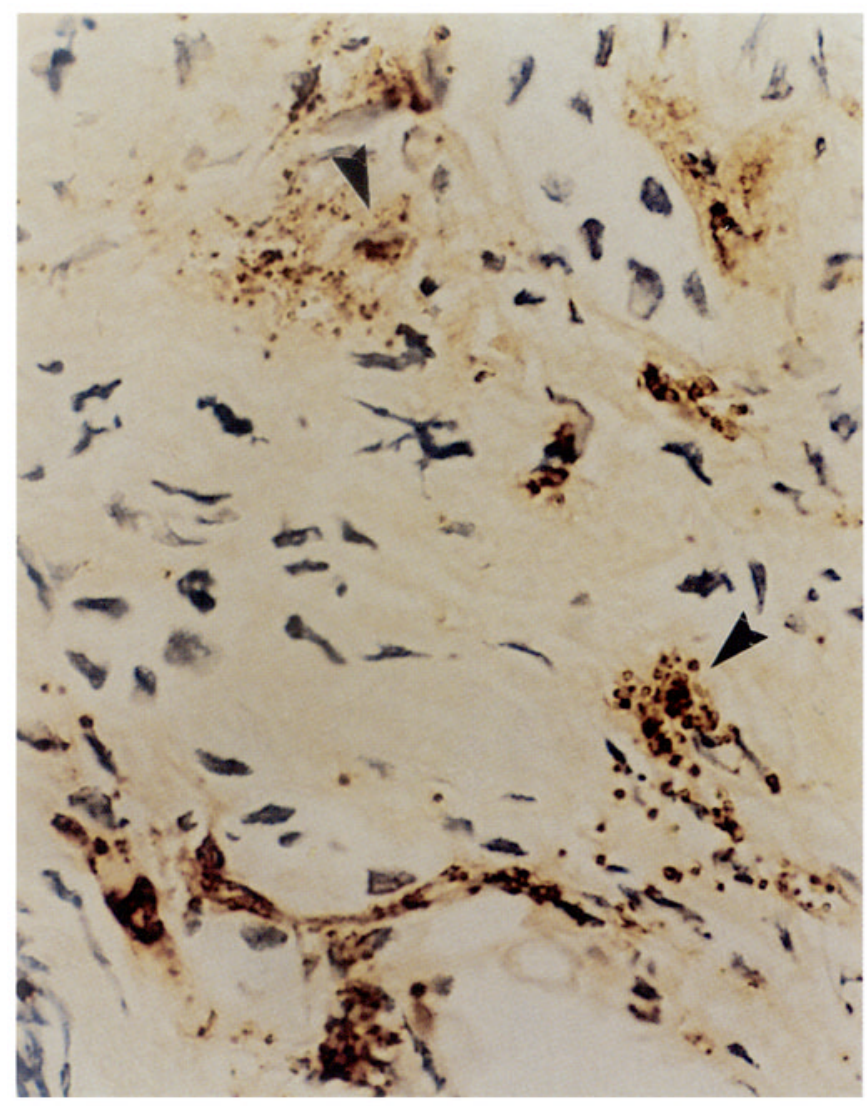

Fig. 3. Degranulating MC in diabetic nephropathy. Anti-tryptase antibody staining revealed the presence of degranulating $\mathrm{MC}$ in the interstitium of diabetic nephropathy renal biopsy tissue. (Immunoperoxidase staining; magnification $\times 875$ )

situ hybridisation type VIII collagen transcripts were localised to cells with size, shape, and distribution consistent with MC (Fig. 7). Sense probe and RNase pre-treatment controls were negative, confirming specificity.

aSMA was detected in interstitial and periglomerular myofibroblasts and was closely associated with the surrounding type VIII collagen-containing fibres (Fig. 8).

\section{Discussion}

Tubulointerstitial fibrosis is an important pathologic feature of diabetic nephropathy, particularly in those patients with associated renal insufficiency [2]. The phenotypes of cells forming the interstitial infiltrate in DN have not been precisely defined to date, most previous studies having concentrated on the glomerular changes taking place in the course of the disease process $[3-6,10]$. In this paper we have demonstrated a tenfold increase in the number of $\mathrm{MC}$ within the interstitium in DN compared with normal kidney tissue. MC were often found in periglomerular and peritubular locations, but never within glomeruli.

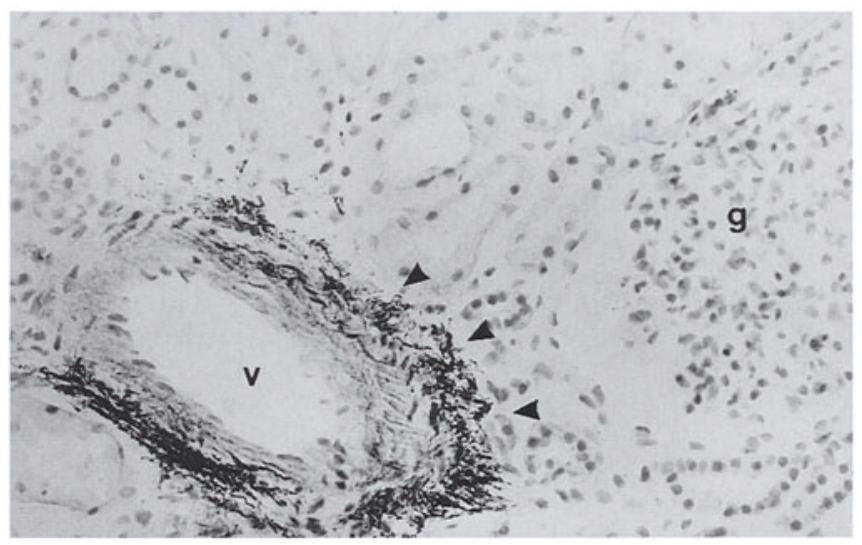

Fig.4. Type VIII collagen expression in normal human kidney tissue. The expression of $\alpha 1$ (VIII) collagen in normal kidney tissue was localized to perivascular fibres (arrows). Periglomerular and interstitial areas showed no reactivity with the anti- $\alpha 1$ (VIII) collagen antibody. (Immunoperoxidase staining; magnification $\times 130 ; \mathrm{g}$, glomerulus; $v$, vessel)

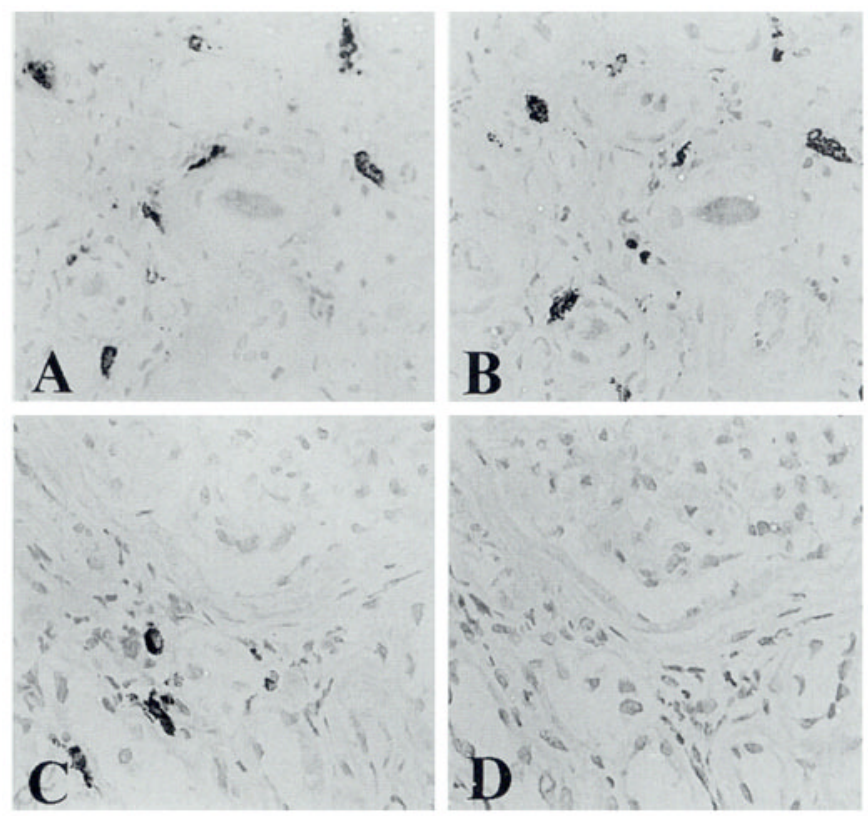

Fig. 5. Tryptase and type VIII collagen staining on sequential diabetic nephropathy sections. Tryptase positive mast cells (A) also expressed $\alpha 1$ (VIII) collagen (B, sequential section to A), demonstrating that mast cells in diabetic nephropathy express type VIII collagen. After collagenase treatment tryptase staining was maintained (C), but no staining for $\alpha 1$ (VIII) collagen (D) could be detected. (Immunoperoxidase staining; magnification $\times 260$ )

Most work on MC has concentrated on their familiar role in acute allergic and parasitic diseases [36]. However, MC are also increasingly recognized as important fibrogenic agents [15], acting on extracellular matrix, and also influencing fibroblast activity. Hence the greatly increased number of MC observed in the interstitium in DN may be integral to the initiation and maintenance of fibrosis. Most MC in DN tissue 
1

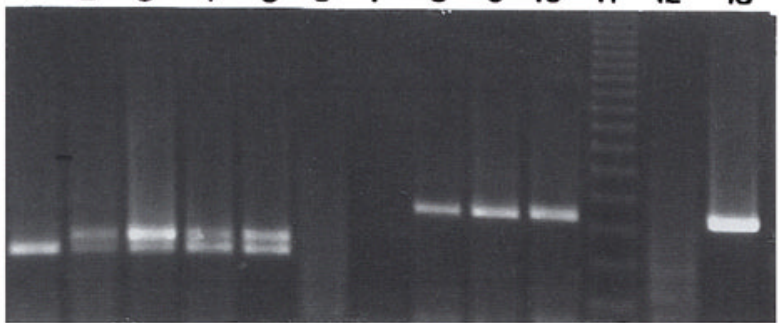

Fig. 6. RT-PCR for $\alpha 1$ (VIII) collagen mRNA. Ethidium bromide stained agarose gel analysis of RT-PCR products obtained with specific primers for the control housekeeping gene, HPRT and $\alpha 1$ (VIII) collagen. Lanes 1-5: Competitive RT-PCR demonstrating equal HPRT mRNA in normal human kidney (lane 2) and in diabetic nephropathy biopsy RNA (lanes 3-5); water control (lane 1) showed only the 380-bp competitor product, while all others exhibited both the competitor and the 395-bp mRNA product, at equivalent concentrations. Lanes 6-10: $\alpha 1$ (VIII) collagen RT-PCR of human renal RNA at the same concentrations used in lanes 2-5. The expected 522-bp band was amplified from the diabetic nephropathy biopsy RNA (lanes 8-10) while normal human kidney RNA (lane 7) and a water control (lane 6) were negative. Lane 11: 123-bp DNA ladder. Lanes 12-13: $\alpha 1$ (VIII) collagen RT-PCR of HMC-1 RNA before and after heparinase treatment, respectively

were of the connective tissue phenotype and stained intensely for type VIII collagen. This is consistent with our earlier observation that MC expressing type VIII collagen are predominantly of the connective tissue phenotype [16].

Furthermore, type VIII collagen was localised to periglomerular fibres and areas of interstitial fibrosis. Accumulation of MC in periglomerular areas of DN tissue was also clearly demonstrated, suggesting that MC could be the source of the type VIII collagenpositive periglomerular fibres. Fibres staining for type VIII collagen were frequently associated with $\alpha$ SMA expression, suggesting a close relationship with activated fibroblasts. However, type VIII collagen was not observed within fibroblasts, in contrast to the strong staining evident in MC.

Type VIII collagen co-localised in fibrotic DN tissue with type I collagen. Previous work suggested that type VIII collagen production precedes or coincides with type I procollagen synthesis [24], so the co-localisation observed is consistent with the hypothesis that type VIII collagen is an early component of new fibrotic tissue in DN. It also supports an earlier report that type VIII collagen can form a molecular scaffold for the deposition of other matrix components [25].

In diabetic biopsies RT-PCR confirmed the presence of $\alpha 1$ (VIII) collagen mRNA, which was localised by in situ hybridisation to interstitial cells with characteristics of MC. Our failure to detect $\alpha 1$ (VIII) collagen mRNA in normal kidney is possibly related to the small number of $\mathrm{MC}$ present $[11,12]$. Rat

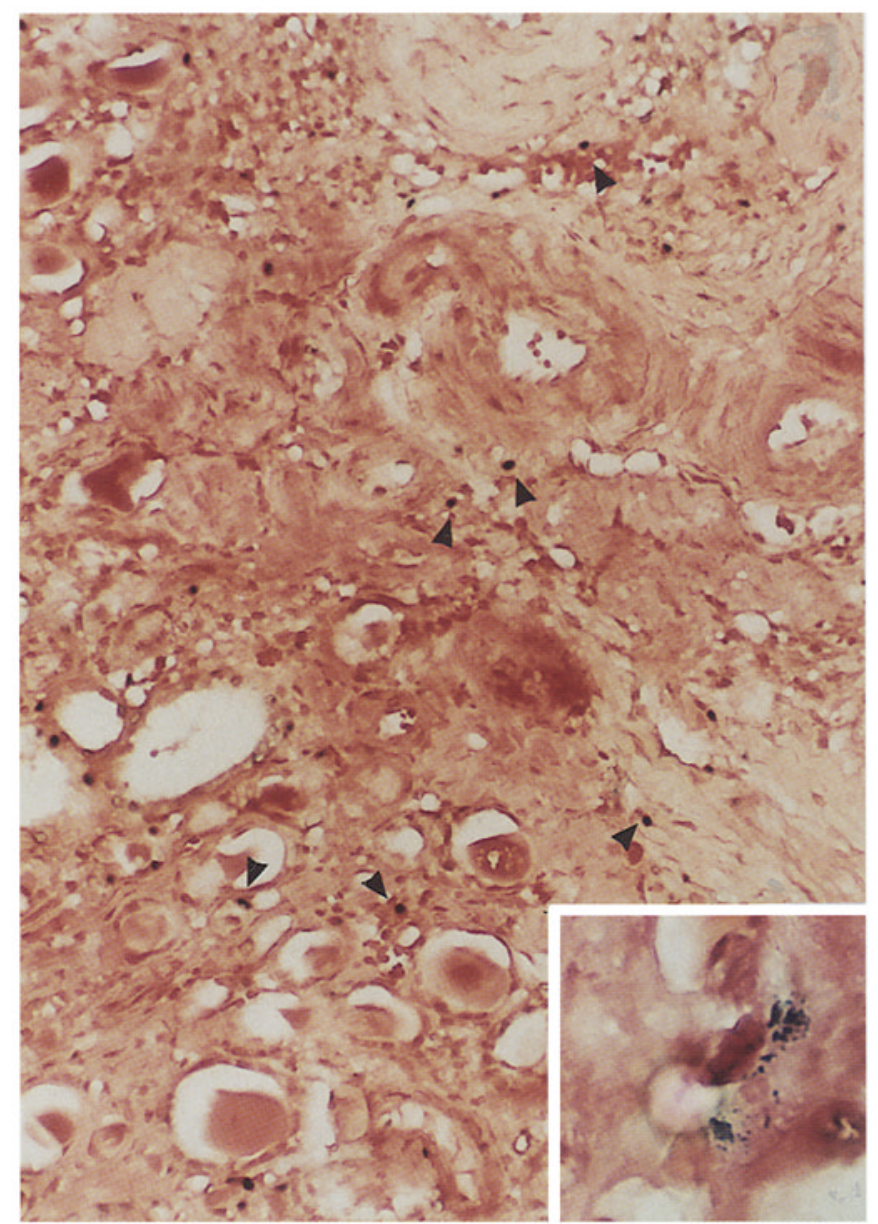

Fig. 7. In situ hybridization for $\alpha$ (VIII) collagen mRNA. Non-isotopic in situ hybridization with digoxigenin labelled oligonucleotides specific for $\alpha 1$ (VIII) collagen mRNA. Type VIII collagen transcripts within interstitial MC (arrows) were labelled as shown by the dark blue reaction product. (Neutral red counterstain; magnification $\times 175$; inset magnification $\times 875$ )

$\alpha 1$ (VIII) collagen mRNA has reportedly been detected in isolated glomeruli, but copy number was low [25]: differences in the amount of tissue available for analysis may account for this apparent discrepancy, rather than any physiological difference between the species.

We also demonstrated by RT-PCR for the first time that a human MC line expresses $\alpha 1$ (VIII) collagen mRNA in vitro. The detection of MC-derived $\alpha 1$ (VIII) collagen mRNA from HMC-1 was facilitated by heparinase treatment, confirming interference of MC heparin with the RT-PCR reaction as described previously [29]. Thompson et al. [15] reported that murine MC synthesise and secrete the extracellular matrix proteins type IV collagen and laminin $\beta 1$ and $\gamma 1$ chains. We have observed in this study that human MC both in vivo and in vitro express a connective tissue protein. MC may therefore contribute directly to extracellular matrix accumulation in DN. 


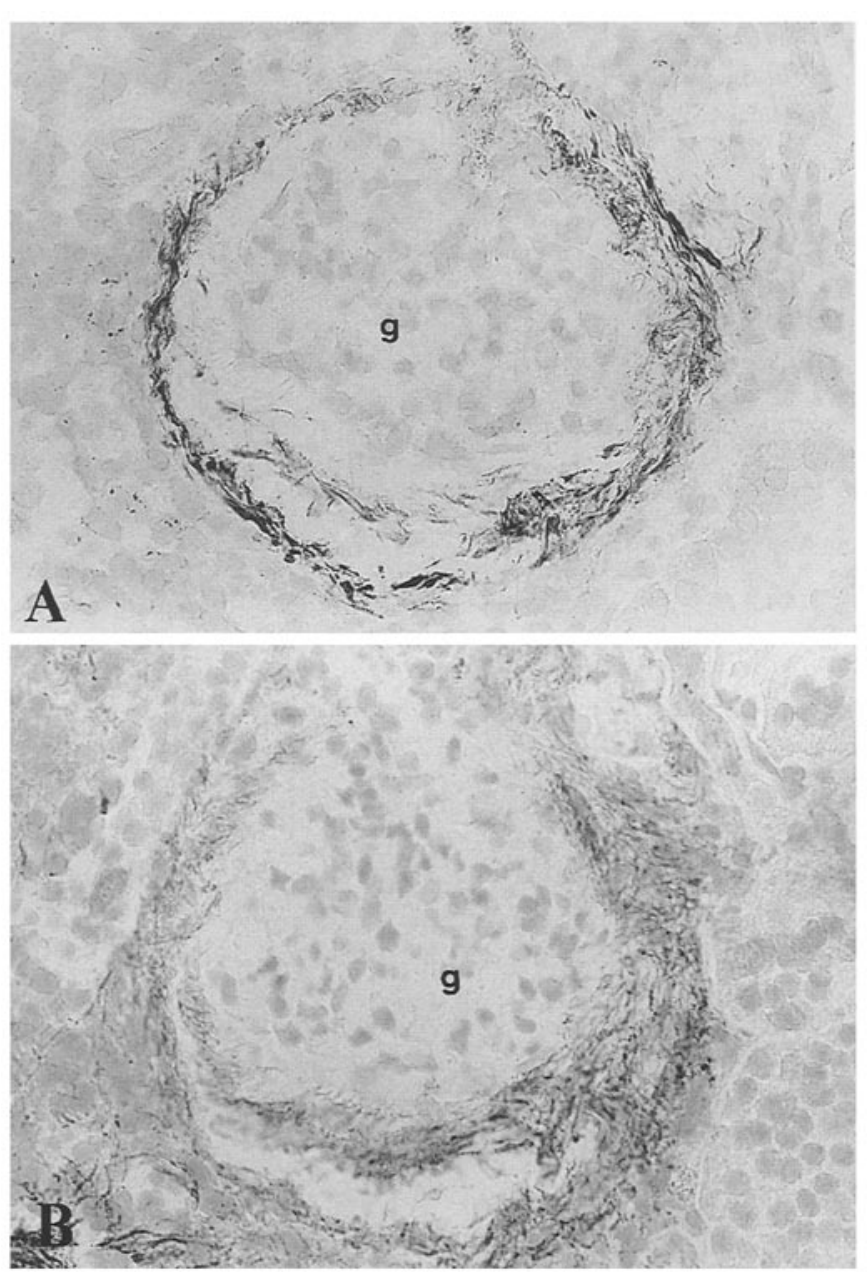

Fig. 8. $\alpha$ SMA expression in diabetic nephropathy. $\alpha$ SMA expression (A) and $\alpha 1$ (VIII) collagen expression (B) on consecutive sections of diabetic nephropathy renal biopsy: $\alpha \mathrm{SMA}$ positive cells were surrounded by type VIII collagen-positive fibres. (Immunoperoxidase staining; magnification $\times 260 ; \mathrm{g}$, glomerulus)

MC can also indirectly influence fibrosis by interacting with fibroblasts. MC can enhance fibroblast migration and proliferation in vitro [37]. MC-derived heparin may be an important factor in this regard. Heparin can induce fibroblast proliferation, and being angiogenic could assist in the formation of granulation tissue [38]. Heparin also influences the expression of $\alpha \mathrm{SMA}$ in fibroblastic cells both in vivo and in vitro [39], confirming a strong effect on fibroblast activation. Our observation of numerous degranulating $\mathrm{MC}$ within the interstitium in DN indicates the release of MC mediators, presumably including heparin, which is a normal component of MC granules. It therefore seems likely that the increased number of MC in the interstitium in DN will substantially upregulate fibroblast activity, accounting for the increased expression of $\alpha S M A$ observed in periglomerular regions. It is also possible that fibroblasts in DN may facilitate the differentiation of MC precursors to mature $\mathrm{MC}$ and help determine their phenotype, since fibroblasts can influence $\mathrm{MC}$ differentiation and function in vitro $[36,40]$.

There have been few reports concerning $\mathrm{MC}$ in renal tissue $[11,12]$. In DN, the number of MC in the interstitium is greatly increased, and it appears that these MC may be actively modulating fibroblast function, as well as directly contributing to the assembly of new extracellular matrix. The interaction between MC and fibroblasts, and the importance of MC products such as type VIII collagen in the pathogenesis of nephropathies associated with fibrosis in general and DN in particular, are under further investigation.

Acknowledgements. The authors appreciate the support provided by Lottery Health Research, Capital Coast Health Trust Fund, University of Otago Trust Fund and Bristol-Myers Squibb. We thank Mr. A. Tan (Malaghan Institute of Medical Research) for culturing the human MC line.

\section{References}

1. Sternberg M, Cohen-Forterre L, Peyroux J (1985) Connective tissue in diabetes mellitus: biochemical alterations of the intercellular matrix with special reference to proteoglycans, collagens, and basement membranes. Diabete Metab 11: $27-50$

2. Ziyadeh FN, Goldfarb S (1995) The diabetic renal tubulointerstitium. Curr Topics Pathol 88: 175-201

3. Kashgarian M, Oshima S, Takeuchi A, Throckmorton D, Rasmussen H (1994) The contribution of mesangial cell collagen synthesis to the pathogenesis of diabetic nephropathy, Contrib Nephrol 107: 132-139

4. Nerlich AG, Schleicher ED, Wiest I, Specks U, Timpl R (1994) Immunohistochemical localization of collagen VI in diabetic glomeruli. Kidney Int 45: 1648-1656

5. Razzaque MS, Koji T, Taguchi T, Harada T, Nakane PK (1994) In situ localization of type III and type IV collagenexpressing cells in human diabetic nephropathy. J Pathol 174: $131-138$

6. Tamsma JT, van den Born J, Bruijn JA et al. (1994) Expression of glomerular extracellular matrix components in human diabetic nephropathy: decrease of heparan sulphate in the glomerular basement membrane. Diabetologia 37: $313-320$

7. Vangelista A, Frasa GM, Severi B, Bonomini V (1989) The role of myofibroblasts in renal interstitial fibrosis and their relationship with fibronectin and type IV collagen. Contrib Nephrol 70: 135-141

8. Myers BD, Ross J, Newton L, Luether J, Perlroth M (1984) Cyclosporine associated chronic nephropathy. N Engl J Med 311: 699-705

9. Bertani T, Perico N, Abbate M, Battaglia C, Remuzzi G (1987) Renal injury induced by long-term administration of cyclosporin A to rats. Am J Pathol 127: 569-579

10. Young AY, Johnson RJ, Alpers CE et al. (1995) Cellular events in the evolution of experimental diabetic nephropathy. Kidney Int 47: 935-944

11. Pavone-Macaluso M (1960) Tissue mast cells in renal diseases. Acta Pathol Microbiol Scand 50: 337-346

12. Colvin RB, Dvorak AM, Dvorak HF (1974) Mast cells in the cortical tubular epithelium and interstitium in human renal disease. Human Pathol 5: 315-326

13. Bienenstock J, Befus AD, Denburg JA (1986) Mast cell heterogeneity: basic questions and clinical implications. In: 
Befus AD, Bienenstock J, Denburg JA (eds) Mast cell differentiation and heterogeneity. Raven Press, New York, pp 391-402

14. Galli SJ (1993) New concepts about the mast cell. N Engl J Med 328: 257-265

15. Thompson HL, Burbelo PD, Gabriel G, Yamada Y, Metcalfe DD (1991) Murine mast cells synthesize basement membrane components. A potential role in early fibrosis. $\mathrm{J}$ Clin Invest 87: 619-623

16. Rüger B, Dunbar PR, Hasan Q et al. (1994) Human mast cells produce type VIII collagen in vivo. Int J Exp Path 75: 397-404

17. Sage H, Pritzl P, Bornstein P (1980) A unique pepsin-sensitive collagen synthesized by aortic endothelial cells in culture. Biochemistry 19: 5747-5755

18. Sawada H, Konomi H, Hirosawa K (1990) Characterization of the collagen in the hexagonal lattice of Descemet's membrane: its relation to type VIII collagen. J Cell Biol 110: 219-227

19. Kapoor S, Sakai LY, Funk S, Roux E, Bornstein P, Sage H (1988) Type VIII collagen has a restricted distribution in specialized extracellular matrices. J Cell Biol 107: 721-730

20. Kittelberger R, Davis PF, Greenhill NS (1989) Immunolocalization of type VIII collagen in vascular tissue. Biochem Biophys Res Commun 159: 414-419

21. Kittelberger R, Davis PF, Flynn DW, Greenhill NS (1990) Distribution of type VIII collagen in tissues: an immunohistochemical study. Connect Tiss Res 24: 303-318

22. Iruela-Arispe ML, Diglio CA, Sage EH (1991) Modulation of extracellular matrix proteins by endothelial cells undergoing angiogenesis in vitro. Arterioscler Thromb 11: 805815

23. Rooney P, Wang M, Kumar P, Kumar S (1993) Angiogenic oligosaccharides of hyaluronan enhance the production of collagens by endothelial cells. J Cell Sci 105: 213-218

24. Sage H, Iruela-Arispe ML (1990) Type VIII collagen in murine development. Association with capillary formation in vitro. Ann NY Acad Sci 580: 17-31

25. Rosenblum ND, Briscoe DM, Karnovsky MJ, Olsen BR (1993) Alpha 1-VIII collagen is expressed in the rat glomerulus and in resident glomerular cells. Am J Physiol 264: F1003-F1010

26. Butterfield JH, Weiler D, Dewald G, Gleich GJ (1988) Establishment of an immature mast cell line from a patient with mast cell leukemia. Leuk Res 12: 345-355

27. Riske F, Hakimi J, Mallamaci M (1991) High affinity human $\operatorname{IgE}$ receptor ( $\mathrm{F} c \varepsilon \mathrm{RI}$ ). Analysis of functional domains of the $\alpha$-subunit with monoclonal antibodies. J Biol Chem 266: 11245-11251
28. Tsukada T, McNutt MA, Ross A, Gown AM (1987) HHF35, a muscle actin-specific monoclonal antibody. Am J Pathol 127: 389-402

29. Tsai M, Miyamoto M, Tam SY, Wang Z, Galli SJ (1995) Detection of mouse mast cell-associated protease mRNA. Heparinase treatment greatly improves RT-PCR of tissue containing mast cell heparin. Am J Pathol 146: 335-343

30. Gilliland G, Perrin S, Blanchard K, Bunn HF (1990) Analysis of cytokine mRNA and DNA: detection and quantitation by competitive polymerase chain reaction. Proc Natl Acad Sci USA 87: 2725-2729

31. Jolly DJ, Okayama H, Berg $P$ et al. (1983) Isolation and characterization of a full-length expressible cDNA for human hypoxanthine phosphoribosyl transferase. Proc Natl Acad Sci USA 80: 477-481

32. Uberla K, Platzer C, Daimantsein T, Blankenstein T (1991) Generation of competitor DNA fragments for quantitiative PCR. PCR Meth Appl 1: 136-140

33. Yamaguchi N, Mayne R, Ninomiya Y (1991) The alpha-1 (VIII) collagen gene is homologous to the alpha-1 (X) collagen gene and contains a large exon encoding the entire triple helical and carboxy-terminal non-triple helical domains of the alpha-1 (VIII) polypeptide. J Biol Chem 266: 4508-4513

34. Irani AA, Schechter NM, Craig SS, DeBlois G, Schwartz LB (1986) Two types of human mast cells that have distinct neutral protease compositions. Proc Natl Acad Sci USA 83: 4464-4468

35. Makino H, Shikita K, Wieslander J et al (1994) Localization of fibril/microfibril and basement membrane collagens in diabetic glomerulosclerosis in type 2 diabetes. Diabet Med 11: 304-311

36. Galli SJ (1990) New insights into "the riddle of the mast cells": microenvironmental regulation of mast cell development and phenotypic heterogeneity. Lab Invest 62: 5-33

37. Levi-Schaffer F, Kupietzky A (1990) Mast cells enhance migration and proliferation of fibroblasts into an in vitro wound. Exp Cell Res 188: 42-49

38. Roche WR (1985) Mast cells and tumors. The specific enhancement of tumor proliferation in vitro. Am J Pathol 119: $57-64$

39. Desmoulière A, Rubbia-Brandt L, Grau G, Gabbiani G (1992) Heparin induces $\alpha$-smooth muscle actin expression in cultured fibroblasts and in granulation tissue myofibroblasts. Lab Invest 67: 716-726

40. Furitsu T, Saito H, Dvorak AM et al. (1989) Development of human mast cells in vitro. Proc Natl Acad Sci USA 86: 10039-10043 